\title{
Clinical study of emergency peripartum hysterectomy for postpartum hemorrhage
}

\author{
Amudha S.*, Sarojini \\ Department of Obstetrics and Gynecology, Bangalore Medical College and Research Institute, Bangalore, India
}

Received: 12 February 2016

Accepted: 08 March 2016

*Correspondence:

Dr. Amudha S.,

E-mail: dramudhabmcri@gmail.com

Copyright: ( $\odot$ the author(s), publisher and licensee Medip Academy. This is an open-access article distributed under the terms of the Creative Commons Attribution Non-Commercial License, which permits unrestricted non-commercial use, distribution, and reproduction in any medium, provided the original work is properly cited.

\section{ABSTRACT}

Background: The objective of this study was to study indications and the outcome of emergency peripartum hysterectomy for PPH in a tertiary care centre and to study the maternal mortality and morbidity in these patients.

Methods: This is an observational study conducted at Vanivilas hospital attached to Bangalore Medical College and Research Institute between January 2014 to December 2015 for 24 months. The women who fulfill the inclusion criteria are studied with respect to parity, gestational age at delivery, route of delivery (vaginal/cesarean), details of instrumental delivery, conservative methods used to control bleeding, ICU admissions and blood transfusions. An analysis of maternal mortality and morbidity was done with respect to development of hypovolemic shock, DIC, anemia, acute kidney injury, septicemia and maternal deaths.

Results: The rate of peripartum hysterectomy is 10.1 per 1000 live births. Placental abnormalities (placenta previa and placenta accreta) are the leading indications $(41.4 \%)$ for peripartum hysterectomy followed by uterine atony (34.5\%). All 29 women received blood and blood product transfusions. 34.5\% developed febrile morbidity, $27.6 \%$ developed DIC, $10.3 \%$ developed acute kidney injury and septicemia and $10.3 \%$ maternal deaths.

Conclusions: PPH is unpredictable in onset, duration and etiology and it remains a major life threatening complication of any delivery. The most common causes of hemorrhage in these women are placental abnormalities and uterine atony. When conservative treatment is not feasible or has failed, prompt peripartum hysterectomy is performed failing which the delay would contribute to the maternal morbidity and mortality.

Keywords: PPH, Uterine atony, Adherent placenta, Peripartum hysterectomy, Maternal morbidity, Maternal mortality

\section{INTRODUCTION}

Severe postpartum hemorrhage (PPH) was reported to occur in $6.7 / 1,000$ deliveries worldwide. ${ }^{1}$ It is one of the leading causes of maternal mortality and morbidity and represents the most challenging complication that an obstetrician will face. ${ }^{2}$ Hemorrhage resulting from uterine rupture and atony has become rare events in the developed countries but this continues to be a major problem in developing countries., ${ }^{3,4}$ Emergency peripartum hysterectomy, although rare in modern obstetrics, is one of the lifesaving surgical procedures in the world, when severe obstetrical hemorrhage fail to respond to conservative treatment. ${ }^{5}$
Peripartum hysterectomy is defined as removal of the uterus (total/subtotal) at the time of cesarean section or following vaginal delivery. Emergency peripartum hysterectomy is the most dramatic operation in modern obstetrics and is generally performed when there is life threatening hemorrhage not responding to medical management or conservative surgical procedures or nonavailability of interventional radiology for uterine artery embolization..$^{6-8}$ Emergency peripartum hysterectomy is usually the safest and quickest procedure performed for refractory bleeding. 


\section{METHODS}

This is an observational study conducted at Vanivilas hospital attached to Bangalore Medical College and Research Institute between January 2014 to December 2015 for 12 months. All 29 women who underwent peripartum hysterectomy for uncontrolled $\mathrm{PPH}$ were included in the study. Details of their age, parity, gestational age at delivery, route of delivery (vaginal/cesarean), details of instrumental delivery (if forceps or ventouse were applied) were noted. Medical methods used to control the PPH, finding of genital tract exploration to rule out traumatic $\mathrm{PPH}$, conservative surgical methods used for the control of bleeding like BLYNCH suture, stepwise devascularisation were noted. Details of ICU admissions and blood transfusions were recorded. An analysis of maternal mortality and morbidity was done with respect to development of hypovolemic shock, DIC, anaemia, acute kidney injury, septicaemia and maternal deaths.

Following statistical methods were applied in the present study to evaluate the data:

1. Cross tabs procedure (Contingency coefficient test)

2. Frequency distribution curve

\section{RESULTS}

The following data was obtained from the present study.

Total no of deliveries during the study period: 2856.

Number of women who underwent peripartum hysterectomy: 29.

The rate of peripartum hysterectomy is 10.1 per 1000 live births.

Table 1: Age distribution.

\begin{tabular}{|l|l|l|}
\hline Age & Number & Percentage \\
\hline$<25$ & 10 & $34.5 \%$ \\
\hline $25-29$ & 10 & $34.5 \%$ \\
\hline $30-34$ & 7 & $24.1 \%$ \\
\hline$>34$ & 2 & $6.9 \%$ \\
\hline Total & 29 & $100 \%$ \\
\hline
\end{tabular}

The age distribution of present study group is shown in table no 1. Youngest woman to undergo the procedure is 20 years and the oldest is 37 years.

There were $5(17.2 \%)$ primis, $12(41.4 \%)$ second gravidas, $9(31 \%)$ third gravidas and $3(10.4 \%)$ women with obstetric score of gravida 4 and above in this study group.

$16(55.2 \%)$ women in this study group had vaginal deliveries and $13(44.8 \%)$ underwent cesarean delivery. Amoung vaginal deliveries $2(6.9 \%)$ had ventouse and 1 $(3.4 \%)$ forceps delivery.

Indications for peripartum hysterectomy are shown in Table 2. Placental abnormalities (placenta previa and placenta accreta) are the leading indications (41.4\%) for peripartum hysterectomy followed by uterine atony (34.5\%).

Table 2: Indications for peripartum hysterectomy.

\begin{tabular}{|lll|}
\hline Indications & Number & Percentage \\
\hline Atonic PPH & 10 & $34.5 \%$ \\
\hline Traumatic PPH & 7 & $24.1 \%$ \\
\hline Placenta previa & 7 & $24.1 \%$ \\
\hline Placenta accreta & 5 & $17.3 \%$ \\
\hline Total & 29 & $100 \%$ \\
\hline
\end{tabular}

Traumatic PPH cases included 2 cases of extended cervical tear, 2 cases of colporrhexis, 1 case of broad ligament haematoma, 2 cases of rupture uterus not manageable by repair.

Table 3: Risk factors for the development of PPH.

\begin{tabular}{|lll|}
\hline Risk factors & Number & Percentage \\
\hline $\begin{array}{l}\text { History of instrumental } \\
\text { evacuation }\end{array}$ & 8 & $27.6 \%$ \\
\hline Previous LSCS & 8 & $27.6 \%$ \\
\hline Grand multipara & 3 & $10.3 \%$ \\
\hline Prolonged labor & 3 & $10.3 \%$ \\
\hline Multiple pregnancy & 1 & $3.4 \%$ \\
\hline DIC & 1 & $3.4 \%$ \\
\hline
\end{tabular}

Out of 7 cases of atonic PPH in 5 cases B-lynch suturing was done before proceeding to hysterectomy. Stepwise devascularisation had been done in 2 and both procedures in 2 women. Out of 5 cases of placenta accreta 4 had undergone cesarean in their previous pregnancy.

Table 4: Maternal morbidity and mortality.

\begin{tabular}{|ll|l|}
\hline Complications & Number & Percentage \\
\hline Febrile morbidity & 10 & $34.5 \%$ \\
\hline DIC & 8 & $27.6 \%$ \\
\hline Wound infection & 4 & $13.8 \%$ \\
\hline Acute kidney injury & 3 & $10.3 \%$ \\
\hline septicaemia & 3 & $10.3 \%$ \\
\hline Maternal deaths & 3 & $10.3 \%$ \\
\hline
\end{tabular}

In this study $22(75.9 \%)$ women underwent total hysterectomy and 7 (24.1\%) subtotal hysterectomy.

Women who had associated risk factors contributing to the development of PPH are shown in table no 3. 27.6\% women had undergone prior cesarean delivery and $27.6 \%$ had undergone prior instrumental evacuation. Both in turn were contributing factors for placenta previa and accrete.

All the 30 cases were shifted to ICU after the procedure. All had multiple blood/ blood product transfusions. Out of 29 cases $13(44.8 \%$ ) had more than five units of blood and blood product transfusions. 
Table number 4 shows the maternal morbidities due to PPH or peripartum hysterectomy in these women. Febrile morbidity $(34.5 \%)$ is the most common morbidity seen followed by DIC (27.6\%).

\section{DISCUSSION}

Despite advances in medicine and surgery, postpartum hemorrhage remains one of the leading causes of maternal morbidity and mortality. Peripartum hysterectomy is performed in the treatment of a lifethreatening obstetric hemorrhage that cannot be controlled by conventional methods. The reported incidence of emergency peripartum hysterectomy varies from 0.24 to 5.09 per 1,000 deliveries in the literature. Our incidence of 10.1 per 1,000 deliveries is comparable with the recent studies. Zeteroglu et al reported the incidence of peripartum hysterectomy in a teaching hospital as 5.09/1,000 deliveries, which is higher than that of other studies. ${ }^{9}$ We found abnormal placentation to be the most common indication for peripartum hysterectomy followed by uterine atony. Similar results are found in the studies done by Tarik et al and Smith J, Mousa HA. ${ }^{4,10}$ In a study conducted by Clark SL and colleagues uterine atony was the most common indication for peripartum hysterectomy followed by placental abnormalities. ${ }^{11}$ In present study 4 cases of placenta accreta were found in previous cesarean cases and 1 had history of curettage in previous pregnancy for missed abortion. Similar results are reported by Umezurike CC and colleagues in Nigeria. In our study $34.5 \%$ had febrile morbidity, much higher than that found in the study done by Kashani and colleagues $(8.7 \%))^{2,12}$ DIC was found in $27.6 \%$ cases, comparable with that of Kashani and colleagues. $^{2} 10.3 \%$ women had acute kidney injury, much higher than that found in the study done by Kastner ES and collegues. ${ }^{3}$ The maternal mortality was $10.3 \%$ in this study group which is similar to that found in the study done by Zeteroglu Y and collegues. ${ }^{9}$

\section{CONCLUSION}

PPH is unpredictable in onset, duration and etiology and it remains a major life threateninig complication of any delivary. The most common causes of haemorrhage in these women are placental abnormalities and uterine atony. Although no risk assessment system can predict all instances where peripartum hysterectomy is needed, a significant percentage of the patients who are at high risk for severe hemorrhage and the subsequent need of emergency hysterectomy can be identified before surgery. The preoperative risk factors include previous history of cesarean section, placenta previa and accreta. Due to the complexity of the surgery and decision making, the involvement of an experienced obstetrician at an early stage is desirable. Proper surgical measures such as hemostatic sutures or uterine or internal iliac artery ligation or embolization are options in attempting uterine conservation particularly in young and haemodynamically stable women. When conservative treatment is not feasible or has failed, prompt peripartum hysterectomy is performed failing which the delay would contribute to the maternal morbidity and mortality.

\section{Funding: Not required}

Conflict of interest: None declared

Ethical approval: The study was approved by the Institutional Ethics Committee

\section{REFERENCES}

1. Carvalho JF, Cubal A, Torres S, Costa F. Emergency Peripartum Hysterectomy: A 10- ISRN Emergency Medicine, Volume 2012 (2012), Article ID 721918, 7 pages.

2. Kashani E, Azarhoush R. Peripartum hysterectomy for primary postpartum hemorrhage: 10 years evaluation; euro. J Exp Bio. 2012;2(1):32-6.

3. Kastner ES, Figueroa R. Emergency peripartum hysterectomy: experience at a community teaching hospital Obstet Gynecol. J. 2002;9(6):971-85.

4. Tarik Y, Zamzami Y. ication of emergency peripartum hysterectomy; in dArch Gynecol obstet. 2003;268:131-5.

5. Lovina S.M. Machado, Emergency peripartum hysterectomy: Incidence, indications, risk factors and outcome; N Am J Med Sci. 2011;3(8):358-61.

6. Knight M. Peripartum hysterectomy in the UK: management and outcomes of the associated haemorrhage; BJOG: An International Journal of Obstetrics \& Gynaecology. 2007;114(11):1380-7.

7. Obstetrical Hemorrhage. In: Cunningham FG, Leveno KJ, Bloom SL, Haulh JC, Gilstrap LC, Wenstrom KD, editors. Williams Textbook of Obstetrics, 24 ${ }^{\text {th }}$ ed. New York: McGraw-Hill, 2014. pp.780-789.

8. Omol Ohonsi A, Olayinka HT. Emergency peripartum hysterectomy in a developing country: $\mathbf{J}$ Obstet Gynecol Can. 2012;34(10):954-60.

9. Ustun ZY, Engin-Ustun Y, Sahin G. Peripartum hysterectomy in a teaching hospital in the eastern region of Turkey. European Journal of Obstetrics Gynecology and Reproductive Biology. 2005;120(1):57-62.

10. Smith J, Mousa HA. Peripartum hysterectomy for primary postpartum hemorrhage. Pubmed -indexed for Medline. 2007

11. Clark SL, Yeh SY, Phelan JP, Bruce S. Emergency hysterectomy for obstetric haemorrhage: obstet gynecol. 1984;64:376-80.

12. Umezurike $\mathrm{CC}, \mathrm{Nkwocha} \mathrm{G}$. treatment for primary postpartum hemorrhage; Niger $J$ Med. 2007;16(3):219-33.

Cite this article as: Amudha, Sarojini. Clinical study of emergency peripartum hysterectomy postpartum hemorrhage. Int J Reprod Contracept Obstet Gynecol 2016;5:1171-3. 